\title{
PENGGUNAAN KONJUNGSI DALAM WACANA KRIMINAL KOLOM BORGOL DI SURAT KABAR RAKYAT BENGKULU EDISI NOVEMBER-DESEMBER 2016
}

\author{
Tri Dina Ariyanti \\ Iming Fentaria \\ Dosen Universitas Dehasen Bengkulu \\ tridina31@yahoo.co.id
}

\begin{abstract}
Abstrak: Ragam bahasa berita lazim digunakan dalam pemberitaan: jurnal, media elektronik (televisi, radio), dan media cetak (majalah, surat kabar). Bahasa berita menyajikan fakta secara utuh dan objektif. Berdasarkan media yang digunakan ragam bahasa tulis ditandai dengan kecermatan menggunakan ejaan dan tanda baca (yang secara tepat dapat melambangkan intonasi), kosa kata, penggunaan tata bahasa dalam pembentukan kata, penyusunan kalimat, paragraf, dan wacana. Ragam ini menekankan penggunaan ragam bahasa baku, ejaan (EYD) yang baku, kosa kata yang baku, bentuk kata berimbuhan, dan kalimat yang lengkap secara gramatikal. Dengan demikian, dalam menggunakan konjungsi pun juga dapat diperhatikan dengan baik agar penyusunan kalimat dan paragraf pun menjadi jelas. Konjungsi berfungsi untuk menghubungkan bagian-bagian kalimat atau kalimat yang satu dengan kalimat yang lain dalam suatu wacana. Tujuan penelitian, yaitu untuk mendapatkan pendeskripsikan Kesalahan Penggunaan Konjungsi dalam Wacana Kriminal Kolom Borgol di Surat Kabar Harian Rakyat Bengkulu Edisi 23 November -23 Desember 2016. Metode yang digunakan dalam penelitian ini adalah deskriptif. Metode deskriptif dalam penelitian ini digunakan untuk mendapatkan pendeskripsian penggunaan konjungsi dalam wacana kriminal kolom borgol di Surat Kabar Harian Rakyat Bengkulu. Bentuk Penggunaan Konjungsi Koordinatif pada Surat Kabar Harian Rakyat Bengkulu menunjukan bahwa penggunaan konjungsi: dan, serta, atau, tetapi, melainkan, padahal, sedangkan. Bentuk Penggunaan Konjungsi Korelatif tidak ditemukan dalam wacana kriminal kolom borgol. Bentuk Penggunaan Konjungsi Subordinatif terdiri dari tiga belas jenis, yang meliputi y: (1) hubungan waktu : sejak, ketika, sementara, serta, setelah, sebelum, hingga, (2) hubungan syarat: jika, bila (3) hubungan pengandaian: tidak ditemukan, (4) hubungan tujuan: agar, (5) hubungan konsesif: walaupun, (6) hubungan pembandingan: sebagaimana, seperti, sebagai (7) hubungan sebab: sebab, karena (8) hubungan hasil: sehingga, sampai, maka, (9) hubungan alat: dengan, tanpa, (10) hubungan cara: dengan, tanpa, (11) hubungan komplementasi: bahwa, (12) hubungan atributif: yang (13) hubungan perbandingan: tidak ditemukan. Bentuk Penggunaan Konjungsi antarkalimat meliputi: kemudian, setelah, selanjutnya, selain itu, bahkan, akan tetapi, namun.
\end{abstract}

Kata kunci: Konjungsi, Surat kabar

Abstract: The kind of news language commonly used in news: journal, electronic media (television, radio) and print media (magazine, news paper). News language present the facts as whole and objective. Based on media that use. The kind of written language marked with accuracy using the spelling and punctuation (that exactly can represent intonation), vocabulary, use of grammar in the formation of words, the preparation of sentence, paragraph and discourse. This kind emphasize use standard language, basic spelling, basic vocabulary, from of the word argumentation, and full sentence are grammatical. Such, in use of conjunction also can be considered in order that arranging sentence and paragraph is clear. The function of conjuction is for connect parts of sentences or sentences on the other sentences in a discourse. The purpose of the research is to get depiction mistake by use of conjunction in criminal kolom Borgol discourse, Harian Rakyat Bengkulu news paper. The form of use conjuction coordinative from Harian Rakyat Bengkulu news paper show that use of conjunction is: and, with, or, but, except, besides, while. The use of conjunction corelative in criminal colom borgol discourse is not found. The use conjunction subordinative compose from 13 kinds, that is: 1. a time : since, when, while, with, after, before, until 2. condition: if, when. 3. Supposition: not found. 4. Purpose: in order, 5. Konsesif: although, 6. Comparation: such as, like, as, 7. Causal: cause, because, 8. Result: until, till, so, 9. Instrument: with, without, 10. Manner: with, without 11. Complementation: that 12. Attributive: the 13. Comparation: not found 14. The form of use conjuction between sentences is: and then, after, next, another, even, but, however.

Keywords: Conjunction, Newspapers 


\section{A. PENDAHULUAN}

Pada saat beradaptasi di lingkungan sosial, seseorang akan memilih bahasa yang digunakan tergantung situasi dan kondisi yang dihadapi. Seseorang akan menggunakan bahasa yang nonstandar (tidak resmi) pada saat berbicara dengan teman-teman dan menggunakan bahasa standar (resmi) pada saat berbicara dengan orang tua atau yang dihormati. Kemampuan untuk menentukan pilihan ragam bahasa tersebut akan sangat membantu dalam berintegrasi di dalam masyarakat. Ragam bahasa dapat dilihat dari segi sarana atau jalur yang digunakan. Dalam hal ini, dapat disebut adanya ragam lisan dan ragam tertulis. Ragam bahasa lisan adalah ragam bahasa yang dituturkan dengan indra mulut. Ragam bahasa tertulis adalah ragam bahasa yang dituangkan melalui simbol-simbol atau huruf-huruf.

Adanya ragam bahasa lisan dan ragam tertulis didasarkan pada kenyataan bahwa bahasa lisan dan bahasa tertulis memiliki struktur yang tidak sama (Hikmat, 2013: 9). Pada saat beradaptasi di lingkungan sosial, seseorang akan memilih bahasa yang digunakan tergantung situasi dan kondisi yang dihadapi. Seseorang akan menggunakan bahasa yang nonstandar (tidak resmi) pada saat berbicara dengan teman-teman dan menggunakan bahasa standar (resmi) pada saat berbicara dengan orang tua atau yang dihormati. Kemampuan untuk menentukan pilihan ragam bahasa tersebut akan sangat membantu dalam berintegrasi di dalam masyarakat.
Ragam bahasa dapat dilihat dari segi sarana atau jalur yang digunakan. Dalam hal ini, dapat disebut adanya ragam lisan dan ragam tertulis. Ragam bahasa lisan adalah ragam bahasa yang dituturkan dengan indra mulut. Ragam bahasa tertulis adalah ragam bahasa yang dituangkan melalui simbol-simbol atau huruf-huruf. Adanya ragam bahasa lisan dan ragam tertulis didasarkan pada kenyataan bahwa bahasa lisan dan bahasa tertulis memiliki struktur yang tidak sama (Hikmat, 2013: 9). Adanya ketidaksamaan struktur ini adalah karena dalam bahasa lisan dapat dibantu oleh unsur-unsur nonlinguistik yang berupa intonasi, gerak-gerik tangan, gelengan kepala, dan lainnya. Sedangkan dalam bahasa tetulis tidak ada. Sebagai penggantinya harus dieksplisitkan secara verbal dan harus lebih menaruh perhatian agar kalimat-kalimat yang disusun dapat dipahami secara baik. Kesalahan atau kesalahpengertian dalam bahasa lisan dapat segera diperbaiki atau diralat. Tetapi dalam bahasa tulis kesalahan atau kesalahpengertian baru dapat diperbaiki ketika kalimat tersebut sudah ditulis.

Ragam bahasa berita lazim digunakan dalam pemberitaan: jurnal, media elektronik (televisi, radio), dan media cetak (majalah, surat kabar). Bahasa berita menyajikan fakta secara utuh dan objektif. Berdasarkan media yang digunakan ragam bahasa tulis ditandai dengan kecermatan menggunakan ejaan dan tanda baca (yang secara tepat dapat melambangkan intonasi), kosa kata, penggunaan tata bahasa dalam pembentukan kata, penyusunan kalimat, paragraf, dan wacana. Ragam ini menekankan penggunaan 
ragam bahasa baku, ejaan (EYD) yang baku, kosa kata yang baku, bentuk kata berimbuhan, dan kalimat yang lengkap secara gramatikal.

Dengan demikian, dalam menggunakan konjungsi pun juga dapat diperhatikan dengan baik agar penyusunan kalimat dan paragraf pun menjadi jelas. Konjungsi berfungsi untuk menghubungkan bagian-bagian kalimat atau kalimat yang satu dengan kalimat yang lain dalam suatu wacana.

Penelitian ini mempunyai tujuan yaitu mendapatkan pendeskripsikan Kesalahan Penggunaan Konjungsi dalam Wacana Kriminal Kolom Borgol di Surat Kabar Harian Rakyat Bengkulu Edisi 23 November--23 Desember 2016. Rumusan masalah dalam penelitian ini adalah bagaimana kesalahan penggunaan konjungsi dalam wacana kriminal Kolom Borgol di Surat Kabar Harian Rakyat Bengkulu Edisi 23 November-23 Desember $2016 ?$

\section{B. LANDASAN TEORETIS}

\section{a) Konjungsi}

Konjungsi atau kata penghubung di dalam bahasa Indonesia itu memiliki tingkat kompleksitas yang tinggi dalam karangmengarang atau tulis-menulis. Kelas kata konjungsi atau yang lazim disebut juga sebagai konjungtor, atau yang dalam literatur lain lazim disebut pula sebagai kata sebagai kata penghubung (Rahardi, 2009: 14). Konjungsi atau kata penghubung dalam bahasa Indonesia itu terbagi empat jenis yaitu (1) konjungsi koordinatif, (2) konjungsi korelatif, (3) konjungsi subordinatif, dan (4) konjungsi antarkalimat. Tiga jenis konjungsi tersebut lazim beroperasi dalam tataran kalimat, sedangkan satu jenis konjungsi terakhir beroperasi dalam tataran wacana (discourse) (Rahardi, 2009: 14).

\section{b) Berita}

Istilah news dalam Inggris untuk maksud berita berasal dari new (baru) dengan konotasi kepada hal-hal yang baru. Dalam hal ini segala yang baru merupakan bahan informasi bagi semua orang yang memerlukannya. Dengan kata lain, semua hal yang baru merupakan bahan informasi yang dapat disampaikan kepada orang lain dalam bentuk berita (news) (Suhandang, 2010: 102-103). Secara etimologis istilah "berita" dalam bahasa Indonesia mendekati istilah "bericht (en)" dalam bahasa Belanda. Besar kemungkinan kedua istilah itu berketurunan mengingat Indonesia lama dijajah Belanda. Dalam bahasa Belanda istilah "bericht (en)" dijelaskan sebagai "mededeling" (pengumuman) yang berakar kata dari "made (delen)" dengan sinonim pada "beekend maken" (memberitahukan, mengumumkan, membuat terkenal) dan "vertelen" (menceritakan atau memberitahukan) (Suhandang, 2010: 103).

Dapat disimpulkan bahwa yang dimaksud dengan berita (news) itu tiada lain adalah laporan atau pemberitahuan tentang segala peristiwa aktual yang menarik perhatian orang banyak. Adapun jenis berita meliputi Berita Langsung (Straight News) dan Berita Tak Langsung (Feature News).

\section{Berita Langsung (Straight News):} pemberitahuan dapat dilakukan dengan cara menyampaikan fakta utama yang terlibat 
dalam peristiwa itu apa adanya secara langsung, baik hal-hal yang menjadi pokok masalah peristiwa itu, ataupun apa yang dikatakan oleh tokoh-tokoh yang terlibat dalam peristiwa itu. Karena itu pula dalam membuat berita langsung (straight new) dapat mengenal jenis-jenis produknya berupa: Matter of fact news, hanya mengemukakan fakta utama yang terlibat dalam peristiwa itu saja. Action news, hanya mengemukakan perbuatan, tindakan (kejadian) yang terlibat dalam peristiwa itu saja. Dengan kata lain, mengisahkan jalannya peristiwa itu. Quote news, hanya mengemukakan kutipan dari apa yang diucapkan oleh para tokoh yang terlibat dalam peristiwanya (Suhandang, 2010: 104105). Untuk banyak menarik perhatian lagi, serta enak dinikmatinya, tidak jarang penyajian berita dilakukan dengan mengkombinasikan atau memadukan dua dari tiga, atau ketiga cara tersebut tadi. Untuk banyak menarik perhatian khalayak terutama dalam memenuhi rasa ingin tahunya, berita disajikan dengan cara memadukan bentuk matter of fact, dan quote news sekaligus menjadi satu sajian (produk jurnalistik) yang sifatnya memberitahu dan menjelaskan keadaan peristiwa yang sebenarnya terjadi.

Berita Tak Langsung (Feature News): Gaya penyampaian informasi atau pemberitahuan untuk bisa menarik perhatian khalayak dapat juga dilakukan dengan cara "diplomatis" dalam arti tidak langsung mengemukakan faktanya, melainkan membangun fakta itu sehingga menarik perhatian atau menimbulkan minat untuk membaca, mendengar, atau menontonnya
(Suhandang, 2010: 108--109). Selain ketujuh berita (matter of Fact news, action news, quote news, features, interpretative, dan reportase), para jurnalis pun mengenal sebutan lain untuk jenis-jenis berita tertentu. Mereka menyebutnya spot news untuk berita yang melaporkan tentang terjadinya suatu peristiwa yang harus segera diketahui khalayak: talky news untuk berita yang memuat pembicaraan atau pidato seseorang atau hasil wawancara dengan seorang; trend news untuk berita yang terus yang berkembang sesuai dengan kelanjutan peristiwanya: depth news untuk berita yang diperoleh dari hasil galian atau ciptaan sendiri dan ditulis secara panjang lebar serta mendalam (Suhandang, 2010: 113-114).

Sesuai dengan tujuan kegiatan jurnalistik dalam rangka mempengaruhi khalayaknya, unsur keindahan sajian produknya sangat diutamakan. Indah dalam arti diminati dan dinikmati. Karena itu selain dibentuk dalam berbagai jenis, berita pun disajikan dengan konstruksi tertentu.

Dalam hal ini, keseluruhan bangunan naskah berita terdiri atas tiga unsur, yaitu headline (judul berita), lead (teras berita), dan body (kelengkapan atau penjelasan berita). Apabila headline merupakan intisari dari berita, maka lead (teras berita) merupakan sari dari berita itu. Selaku sari dari beritanya, lead merupakan laporan singkat yang bersifat klimaks dari peristiwa yang dilaporkannya. Untuk memenuhi rasa ingin tahu pembacanya secara cepat, lead disusun sedemikian rupa sehingga bisa menjawab pertanyaan hakiki yang selalu timbul dari hati nurani pembacanya, atau pendengar radio dan 
penonton televisi, yaitu pertanyaan yang dirumuskan sebagai $5 \mathrm{~W}+1 \mathrm{H}$ (what, who, when, where, why, dan how).

Dengan demikian, baik pembaca, pendengar, atau pun penonton akan segera tahu mengenai persoalan pokok dari peristiwa yang dilaporkannya.

Rakyat Bengkulu adalah surat kabar harian yang terbit di Kota Bengkulu. Surat kabar ini termasuk dalam grup Jawa Pos. Koran ini pertama kali terbit tahun 2001. Surat kabar Rakyat Bengkulu memiliki beberapa kategori berita utama, metropolis, pemilu, hukum, olahraga, dan sosok. Surat kabar Rakyat Bengkulu telah tersebar dan dinikmati masyarakat luas di beberapa kabupaten Provinsi Bengkulu. Artinya, surat kabar ini merupakan surat kabar terbesar di Provinsi Bengkulu. Bahasa berita atau laporan surat kabar, tabloid, majalah, radio, televisi, dan media on line internet yang tidak akrab di mata, telinga, dan benak khalayak, tidak layak disebut bahasa jurnalistik, bahkan harus jelasjelas ditolak sebagai bahasa jurnalistik. Sudah saatnya lembaga-lembaga pemantau media massa lebih vokal dalam menyuarakan dan memperjuangkan hak-hak dasar masyarkat dalam menerima informasi yang aktual, benar, lengkap, akurat, jelas-jernih, dan terpercaya dari media.

Secara etimologis, jurnalistik diartikan sebagai kegiatan untuk menyiapkan, mengedit, dan menulis untuk surat kabar, majalah, atau berkala lainnya. Dirumuskan dalam leksikon komunikasi, jurnalistik adalah pekerjaan mengumpulkan, menulis, menyunting, dan menyebarkan berita dan karangan untuk surat kabar, majalah, dan media massa lainnya seperti radio dan televisi.

\section{METODE}

Metode deskriptif merupakan metode penelitian yang berusaha menggambarkan dan menginterpretasi objek sesuai dengan apa adanya (Sukardi, 2011: 157). Metode yang digunakan dalam penelitian ini adalah deskriptif.

Metode deskriptif dalam penelitian ini digunakan untuk mendapatkan pendeskripsian penggunaan konjungsi dalam wacana kriminal kolom borgol di Surat Kabar Harian Rakyat Bengkulu. Teknik yang digunakan untuk mengumpulkan data dalam penelitian ini dokumentasi. Langkah-langkah pengumpulan data yaitu (1) Mengumpulkan surat kabar Harian Rakyat Bengkulu mengenai berita kriminal kolom borgol, (2) Data yang akan diambil diseleksi terlebih dahulu dengan cara membaca setiap berita tentang kriminal kolom borgol, (3) Menandai konjungsi-konjungsi yang terdapat di dalam surat kabar Rakyat Bengkulu tentang wacana kriminal kolom borgol, (4) Mencatat konjungsi-konjungsi yang terdapat di dalam wacana kriminal kolom borgol pada surat kabar Harian Rakyat Bengkulu. Adapun analisis data penelitian ini adalah (1) mengidentifikasi konjungsi koordinatif, (2) mengidentifikasi konjungsi korelatif, (3) mengidentifikasi konjungsi subordinatif, (4) mengidentifikasi konjungsi antarkalimat, dan (5) kesimpulan, dari hasil identifikasi dan pembahasan. 


\section{HASILPENELITIAN DAN PEMBAHASAN}

Data penelitian ini diperoleh dengan cara mengumpulkan surat kabar Harian Rakyat Bengkulu mengenai wacana kriminal kolom borgol. Surat kabar tersebut diidentifikasi dari segi jenis-jenis konjungsi yakni koordinatif, korelatif, subordinatif, dan antarkalimat. Beberapa jenis konjungsi tersebut dimasukan ke dalam tabel dilihat dari penggunaannya di dalam surat kabar tersebut.

Bentuk Penggunaan Konjungsi Koordinatif pada Surat Kabar Harian Rakyat Bengkulu: Berdasarkan analisis data menunjukan bahwa penggunaan konjungsi koordinatif yang digunakan di surat kabar Harian Rakyat Bengkulu pada wacana kriminal kolom borgol dari 23 November sampai 23 Desember 2016 yakni digunakannya konjungsi: dan, serta, atau, tetapi,melainkan, padahal, sedangkan. Bentuk Penggunaan Konjungsi Korelatif pada Surat Kabar Harian Rakyat Bengkulu: Konjungsi korelatif tidak ditemukan dalam wacana kriminal kolom borgol pada surat kabar harian Rakyat Bengkulu dari 23 November sampai 23 Desember 2016.

Bentuk Penggunaan Konjungsi Subordinatif pada Surat Kabar Harian Rakyat Bengkulu: Konjungsi suborinatif terdiri dari tiga belas jenis, berdasarkan analisis data, konjungsi yang digunakan dalam surat kabar harian Rakyat Bengkulu dari 23 November sampai 23 Desember 2016 yaitu: (1) hubungan waktu : sejak, ketika, sementara, serta, setelah, sebelum, hingga, (2) hubungan syarat: jika, bila (3) hubungan pengandaian: tidak ditemukan, (4) hubungan tujuan: agar, (5) hubungan konsesif: walaupun, (6) hubungan pembandingan: sebagaimana, seperti, sebagai (7) hubungan sebab: sebab, karena (8) hubungan hasil: sehingga, sampai, maka, (9) hubungan alat: dengan, tanpa, (10) hubungan cara: dengan, tanpa, (11) hubungan komplementasi: bahwa, (12) hubungan atributif: yang (13) hubungan perbandingan: tidak ditemukan.

Bentuk Penggunaan Konjungsi Antarkalimat pada Surat Kabar Harian Rakyat Bengkulu yaitu: kemudian, setelah, selanjutnya, selain itu, bahkan, akan tetapi, namun. Dengan demikian, setelah memperoleh data berupa penggunaan konjungsi pada wacana kriminal kolom borgol, berikut akan dipaparkan pembahasan dari penggunaan konjungsi pada surat kabar Rakyat Bengkulu.

Penelitian ini membahas mengenai wacana kriminal kolom borgol. Adapun yang diteliti dalam penelitian ini mengenai kesalahan dalam penggunaan konjungsi. Berbagai kesalahan jenis konjungsi yang digunakan terdapat pada edisi 23 November sampai dengan 23 Desember 2016.

Bagian dari konjungsi koordinatif yakni: seperti dan, serta, atau, tetapi, melainkan, padahal, sedangkan. Ketujuh konjungsi koordinatif tersebut sudah digunakan dengan cukup baik dalam wacana kriminal kolom borgol di surat kabar harian Rakyat Bengkulu. Sementara itu, Konjungsi korelatif yang meiputi; baik...maupun, tidak hanya... tetapi juga, bukan hanya...melainkan juga, 
demikian... sehingga, sedemikian rupa...sehingga, apakah...atau, entah...entah, jangankan...pun, tidak ada satu pun yang digunakan. Padahal dalam kalimat pada wacana tersebut bisa digunakan secara bervariasi.

Konjungsi subordinatif meliputi: hubungan waktu: sejak, semenjak, sedari, sewaktu, ketika, tatkala, sementara, begitu, seraya, selagi, selama, serta, sambil, demi, setelah, sesudah, sebelum, sehabis, selesai, seusai, hingga, sampai. Beberapa konjungsi yang digunakan dalam kolom borgol tersebut sejak, ketika, sementara, serta, setelah, sebelum, hingga. Hubungan syarat: jika, jiakalau, asalkan, bila, manakala. Konjungsi subordinatif dalam hubungan syarat didapat penggunaan jika, bila. Hubungan pengandaian: andaikan, seandainya, umpamanya, sekiranya. Dari konjungsi subordinatif yang lain hanya pengandaian yang tidak digunakan konjungsinya. Hubungan tujuan: agar, supaya, biar. Konjungsi yang digunakan hanya satu yaitu agar.

Hubungan konsesif: biarpun, meski, meskipun, walau, walaupun, sekalipun, sungguhpun, kendati, kendatipun. Ditemukan hanya satu konjungsi yang digankan dalam wacana tersebut yakni walaupun. Hubungan pembandingan: seakan-akan, seolah-olah, sebagaimana, seperti, sebagai, laksana, ibarat, daripada, alih-alih. Beberapa yang digunakan konjungsinya yaitu sebagaimana, seperti, sebagai.

Hubungan sebab: sebab, karena, oleh karena, oleh sebab. Dua konjungsi yang digunakan yakni sebab dan karena. Hubungan hasil: sehingga, sampai, sampai-sampai, maka, makanya. Konjungsi yang terdapat dalam wacananya adalah sehingga, sampai, maka. Hubungan alat: dengan, tanpa. Kedua konjungsi ini digunakan dan hampir setiap wacana menggunakan. Hubungan cara: dengan, tanpa. Kedua konjungsi ini sama halnya dengan hubungan alat, hampir di setiap wacana surat kabar Rakyat bengkulu menggunakan konjungsi tersebut. Hubungan komplementasi: bahwa. Hanya satu konjungsi komplementasi ini yakni menggunakan konjungsi bahwa. Hubungan atributif: yang. Konjungsi ini digunakan dan terdapat dalam wacana. Hubungan perbandingan: sama ... dengan, lebih ... dari, lebih ... daripada. Dari beberapa konjungsi perbandingan ini tidak ada satu pun yang menggunakan konjungsi ini. Konjungsi antarkalimat meliputi: biarpun demikian, biarpun begitu, sekalipun demikian, sekalipun begitu, walaupun demikian, walaupun begitu, meskipun demikian, meskipun begitu, sungguhpun demikian, sungguhpun begitu, kemudian, sesudah itu, setelah itu, selanjutnya, tambahan pula, lagi pula, selain itu, sebaliknya, sesungguhnya, bahwasanya, malahan, malah, bahkan, akan tetapi, namun, kecuali itu, dengan demikian, oleh karena itu, oleh sebab itu, sebelum itu. Dari hasil penelitian di dapat bahwa konjungsi antarkalimat yang digunakan adalah kemudian, selanjutnya, selain itu, bahkan, akan tetapi, namun. Teori-teori di atas merupakan acuan dalam penelitian ini, berbagai hal kesalahan konjungsi yang ditemukan dan masih banyak konjungsi yang tidak digunakan dalam kalimat wacana tersebut. Salah satu jenis konjungsi 
yang tidak ditemukan di dalam wacana kriminal kolom borgol adalah konjungsi korelatif, padahal dapat digunakan di beberapa kalimat.

\section{E. PENUTUP}

Penelitian ini membahas tentang penggunaan konjungsi dalam wacana kriminal kolom borgol di surat kabar Rakyat Bengkulu edisi 23 November sampai 23 Desember 2016. Dari pembahasan penelitian ini disimpulkan bahwa penggunaan konjungsi dalam surat kabar Rakyat Bengkulu belum efektif dan variatif. Hal ini, disebabkan oleh kurangnya pengetahuan penulis berita atau pun editor dalam pemahaman tentang jenis-jenis dan keberfungsian konjungsi. Penggunaan konjungsi masih terdapat kesalahan dalam penulisannya seperti konjugsi tetapi dan melainkan harusnya menggunakan tanda koma.

\section{DAFTAR PUSTAKA}

Arikunto, Suharsimi. 2010. Prosedur Penelitian: Suatu Pendekatan Praktik. Jakarta: Rineka Cipta.

Hikmat, Ade dan Nani Solihin. Bahasa Indonesia. Jakarta: PT Gramedia Widiasarana.

H.S., Widjono. 2012. Bahasa Indonesia: Mata Kuliah Pengembangan Kepribadian di Perguruan Tinggi. Jakarta: Grasindo.

Moleong, Lexy. 2005. Metodologi Penelitian Kualitatif. Bandung: PT Remadja Rosdakarya.. Bandung: PT Remadja Rosdakarya.

Rahardi, Kunjana. 2009. Penyuntingan Bahasa Indonesia untuk Karang Mengarang. Jakarta: Erlangga.

Sugihastuti dan Siti Saudah. 2016. Buku Ajar Bahasa Indonesia Akademik. Yogyakarta: Pustaka Pelajar.

Suhandang, Kustadi. 2010. Pengantar Jurnalistik: Seputar Organisasi, Produk, dan Kode Etik. Bandung: Nuansa.

Sukardi. 2011. Metodologi Penelitian Pendidikan:Kompetensi dan Praktiknya. Jakarta: Bumi Aksara.

Widarmanto, Tjahjono. 2015. Pengantar Jurnalistik: Panduan Awal Penulis dan Jurnalis. Yogyakarta: Araska. 